\title{
Feline Infectious Peritonitis in a Male Persian Cat
}

\author{
Pankaj Gaonkar, Noopur Halmare, Siddhart Jamdade, \\ Prashant Sonkusale and Nitin Kurkure*
}

Department of Veterinary Pathology, Nagpur Veterinary College, Nagpur, India

*Corresponding author

\section{A B S T R A C T}

\section{Keywords}

Histopatology,

Clinical signs,

Peritonitis,

Multifocal necrosis

Article Info

Accepted:

12 December 2018

Available Online:

10 January 2019
Feline infectious peritonitis (FIP) is irremediable disease of cats. It is known to be caused by corona virus. During routine necropsy a case of peritonitis was encountered in white Persian cat which was investigated for pathology. Fever, anorexia, jaundice, diarrhoea, weight loss and dyspnoea were the clinical sings reported. Carcass was icteric. Spleen revealed yellowish-white raised nodule scattered over its surface. Liver revealed multifocal necrosis. Kidney was severely congested. Fibrinous exudates were deposited on various visceral organs. Abdominal cavity was filled with yellow, viscous fluid. Histopathological examination was carried out to determine the extent of damage to affected organs. Diagnosis was achieved on basis of clinical signs and pathognomonic histopathological lesions.

\section{Introduction}

Feline infectious peritonitis (FIP) is deadly, incurable disease of cats which is reported throughout the world. Though known to be caused by feline corona virus (Hartmann, 2005), it has been complicated by secondary bacterial invaders. Despite of advancement in research till date there is no cure for FIP (Kipar et al., 2014). The disease is mainly prevalent in young, purebred and sexually intact male cats (Rohrbach et al., 2001). FIP is recorded mostly in pure breeds which might owe to inbreeding of cats (Benetka et al., 2004). There are two forms of FIP - wet and dry form. Wet form is characterized by presence of inflammatory exudates into body cavities. Dry form is characterized by its non effusive nature and granulomatous involvement of parenchymatous organs. Although both forms are fatal, the wet form is more common and progressive (Pedersen et al., 2009). The present paper we report a case of FIP in Persian male cat with major focus on its clinical features and histopathological diagnosis.

\section{Materials and Methods}

\section{Post mortem examination}

A carcass of 1 year and 2 months old domesticated Persian intact male cat weighing about $5.5 \mathrm{~kg}$ was presented at Department of 
Veterinary Pathology, Nagpur Veterinary College, India for post-mortem. Fever, anorexia, jaundice, diarrhoea, weight loss and dyspnoea were the clinical sings reported. Necropsy was conducted with standard procedure.

\section{Histopathological examination}

Morbid tissues from these organs were collected in $10 \%$ formal saline. These tissues were further processed to form paraffin blocks. Sections of 4 micron were taken and detail histopathological examination was carried out to study the microscopic lesions (Luna, 1968).

\section{Results and Discussion}

Clinical signs observed by physician and reported were fever, anorexia, ascities, jaundice, vomition and dyspnoea. Expression of clinical signs depends upon organs affected with granulomatous and Vasculitis lesion (Addie et al., 2009). The clinical signs recorded in this study were similar to previous reports (Wolfe et al., 1966 and Montali and
Stramdberg, 1972). The cat was emaciated and dehydrated. Peritoneal cavity revealed presence of approximately $300 \mathrm{ml}$ of yellow viscous fluid (Fig. 1). All the abdominal organs were covered with yellowish fibrinous material. Spleen revealed yellowish-white raised nodule scattered over its surface (Fig. 2). Liver showed multifocal necrosis along with fibrinous exudates (Fig. 3). Kidneys were severely congested an enlarged (Fig. 4). Gross lesions observed in the present case were also reported earlier by Kipar and Meli (2014).

Microscopic view of granulomatous lesion on spleen showed necrotic centre along with presence of multinucleated giant cell (Fig. 57). Whereas germinal centre in spleen had depleted of lymphocytes (Fig. 8). Presence of multinucleated giant cell in spleen is hallmark of the FIP infection in cats. FIP infected cats show apoptosis and depletion of T-cell in lymphoid organs as a result of soluble mediators released at time of infection (Bart et al.,1996) which might have contributed for the depletion of lymphocytes. The serosal surface of liver was covered by fibrinous layer along with infiltration of leukocytes (Fig. 9).

Fig.1 Approximately 300ml of fluid

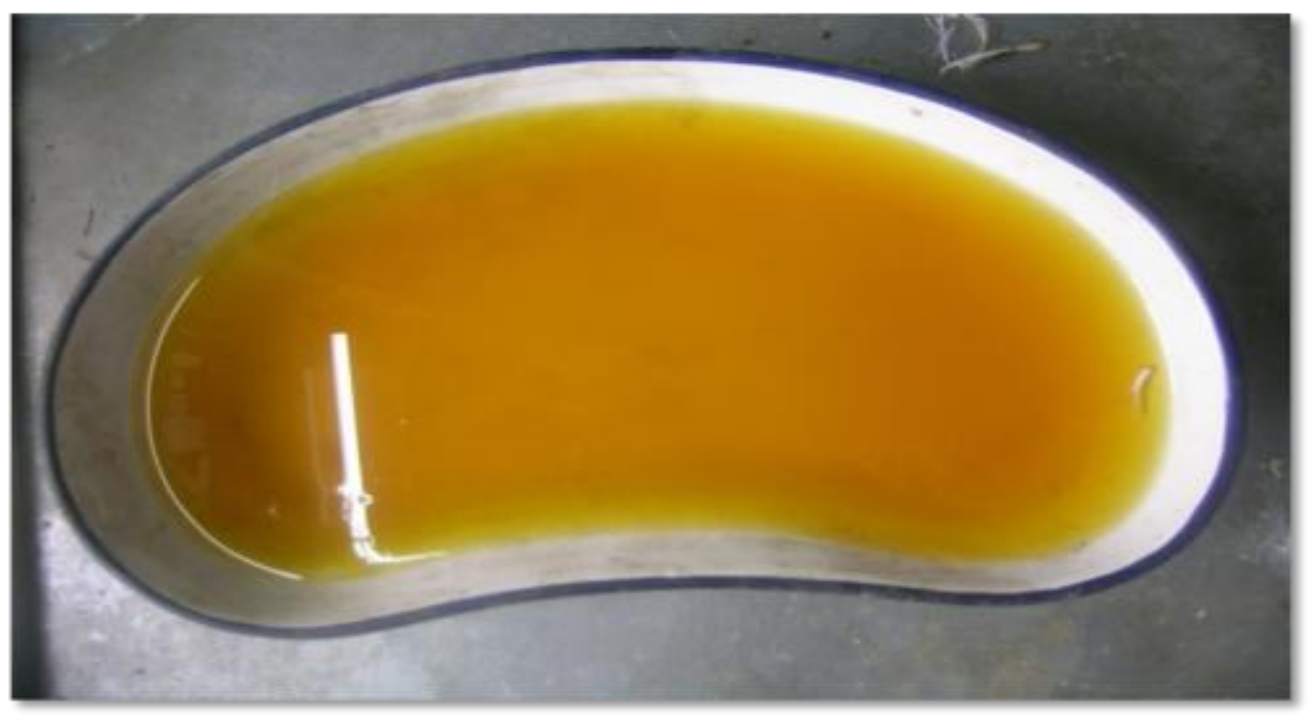


Int.J.Curr.Microbiol.App.Sci (2019) 8(1): 1446-1453

Fig.2 Spleen revealed yellowish-white raised nodule

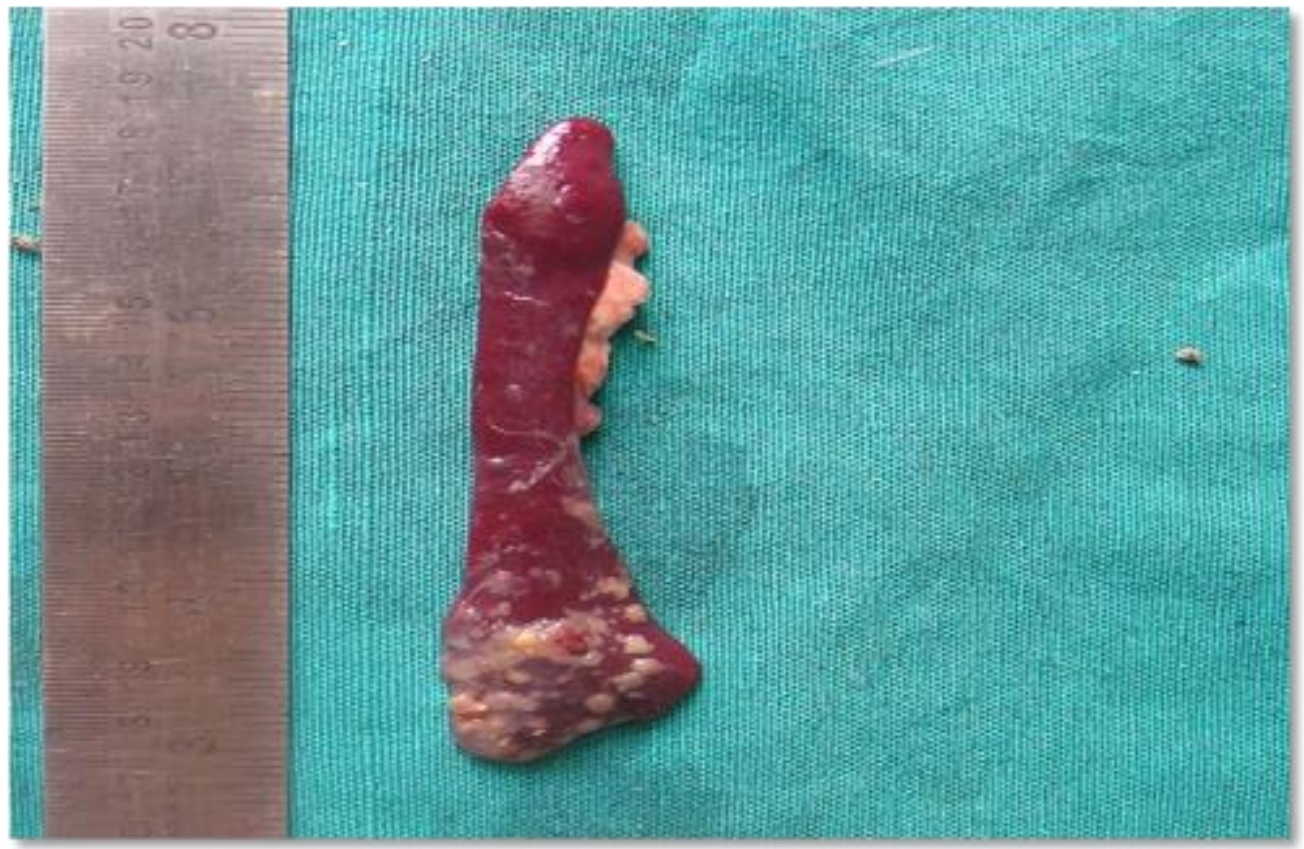

Fig.3 Liver revealed multifocal necrosis scattered over its surface

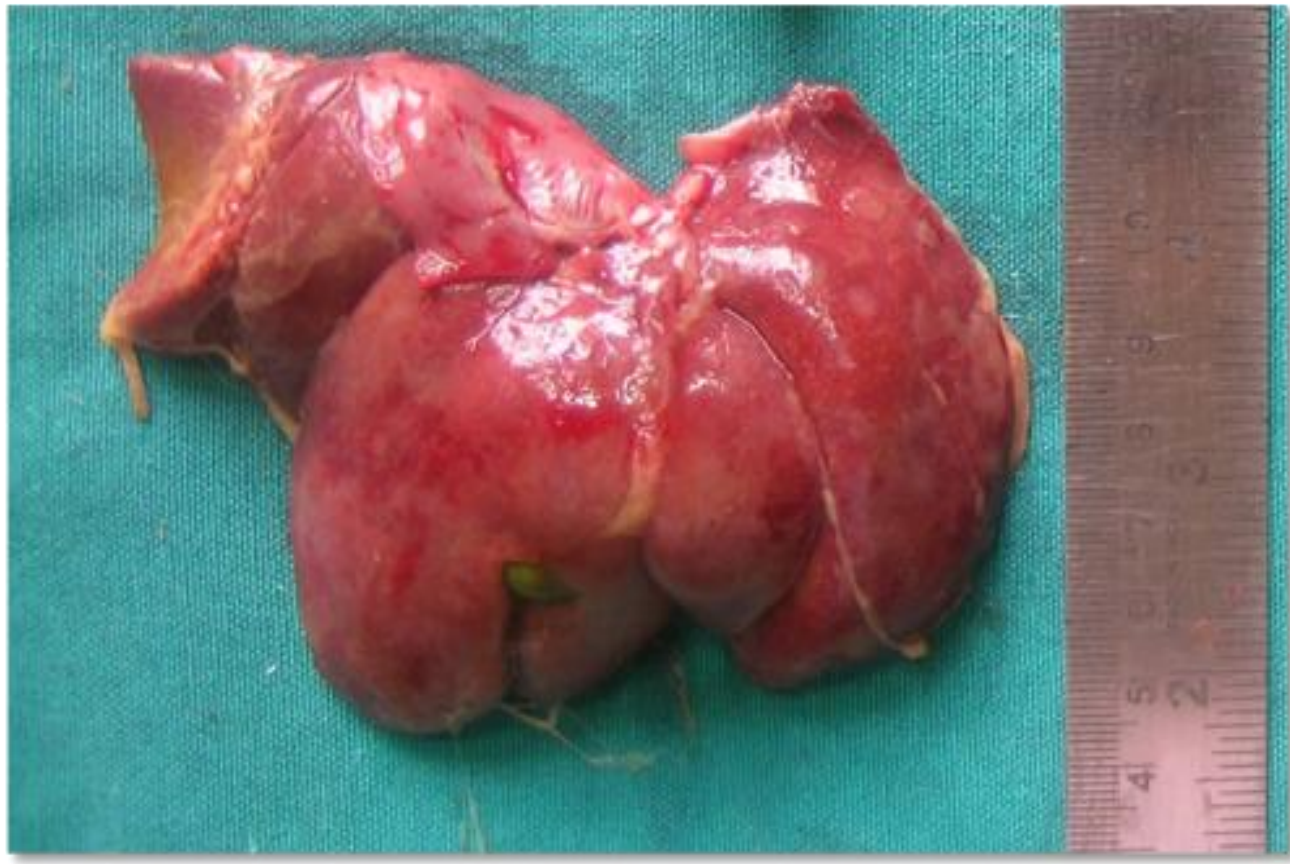


Int.J.Curr.Microbiol.App.Sci (2019) 8(1): 1446-1453

Fig.4 Kidney was severely congested and enlarged

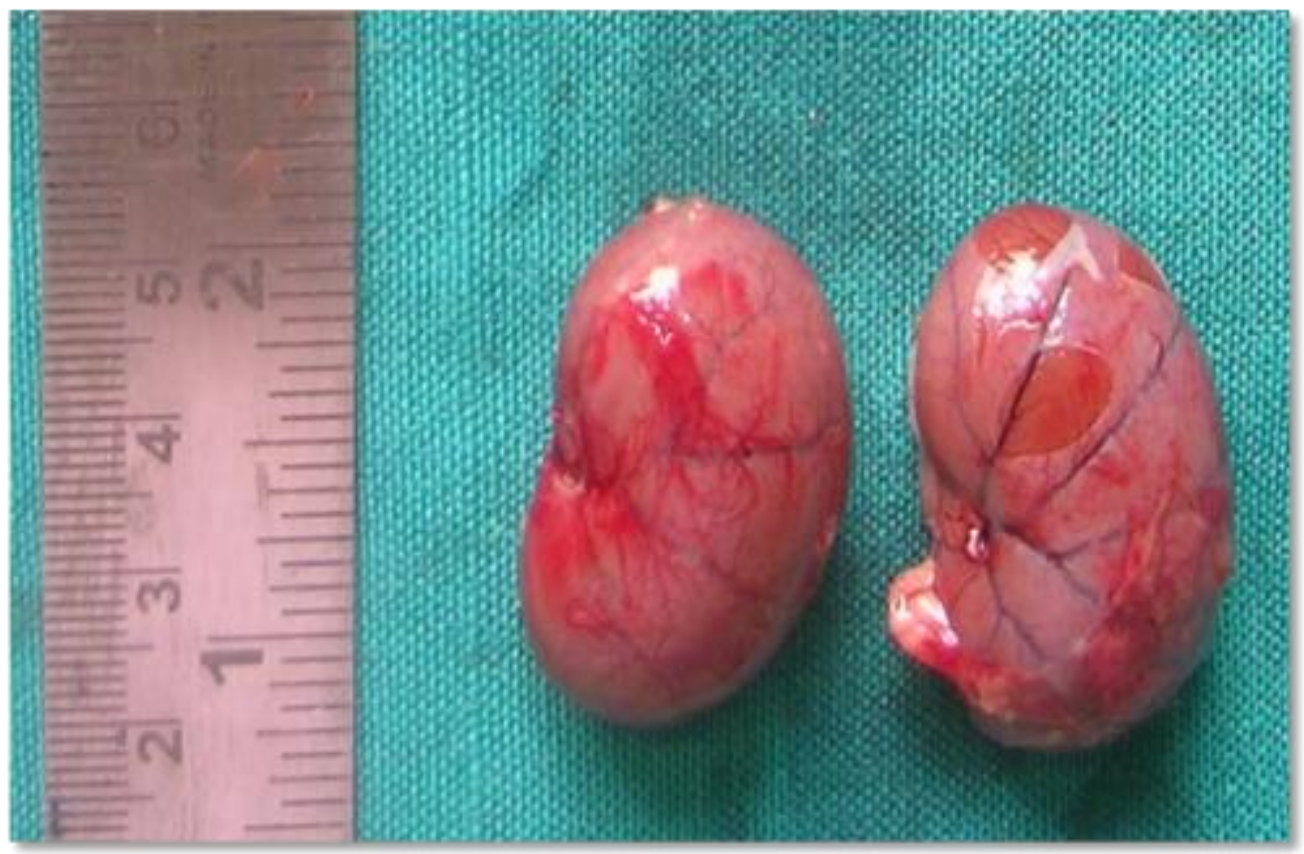

Fig.5 Histological section of nodule on spleen. H\&E

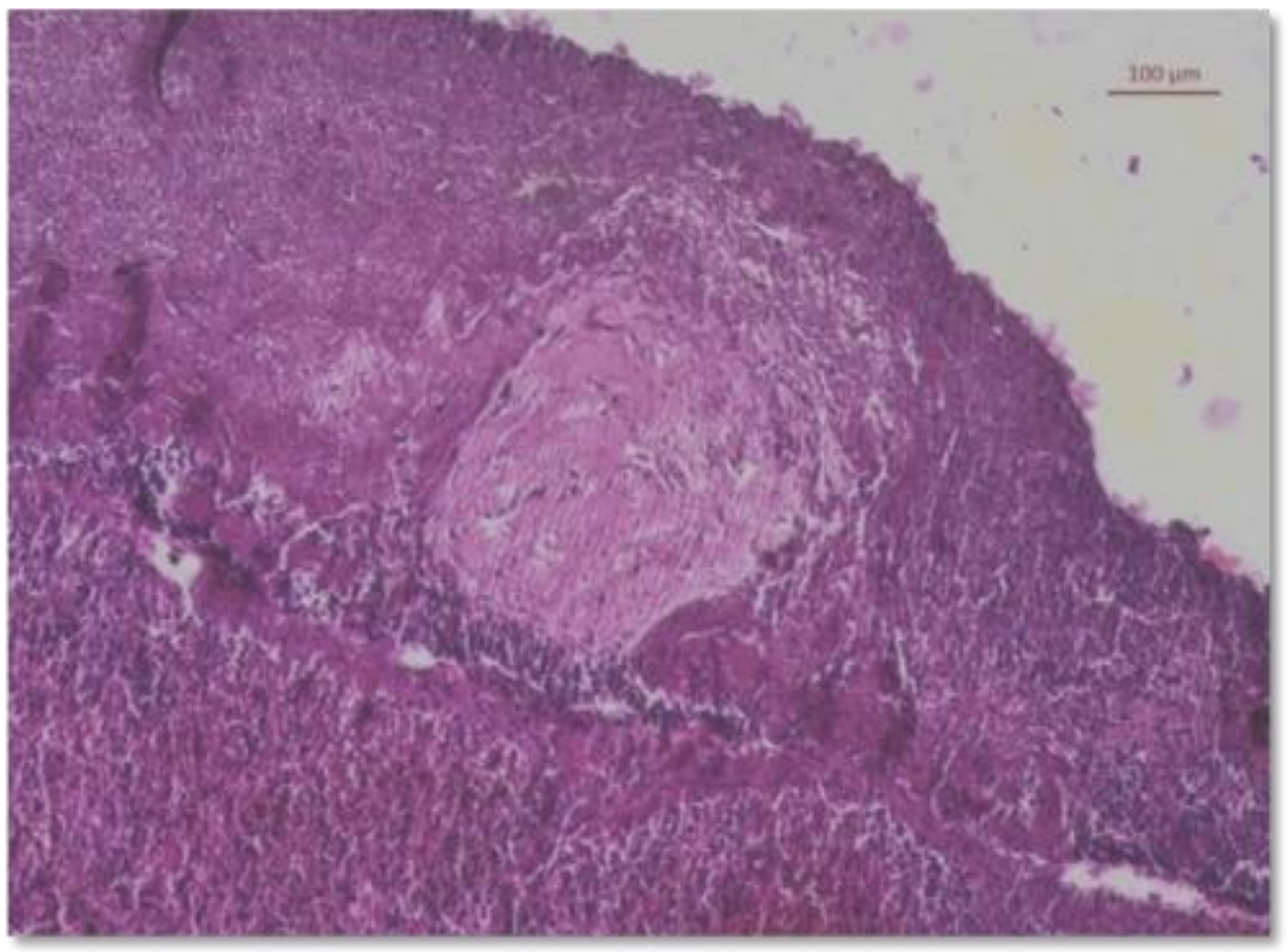


Fig.6 Histological section of nodule on spleen. H\&E

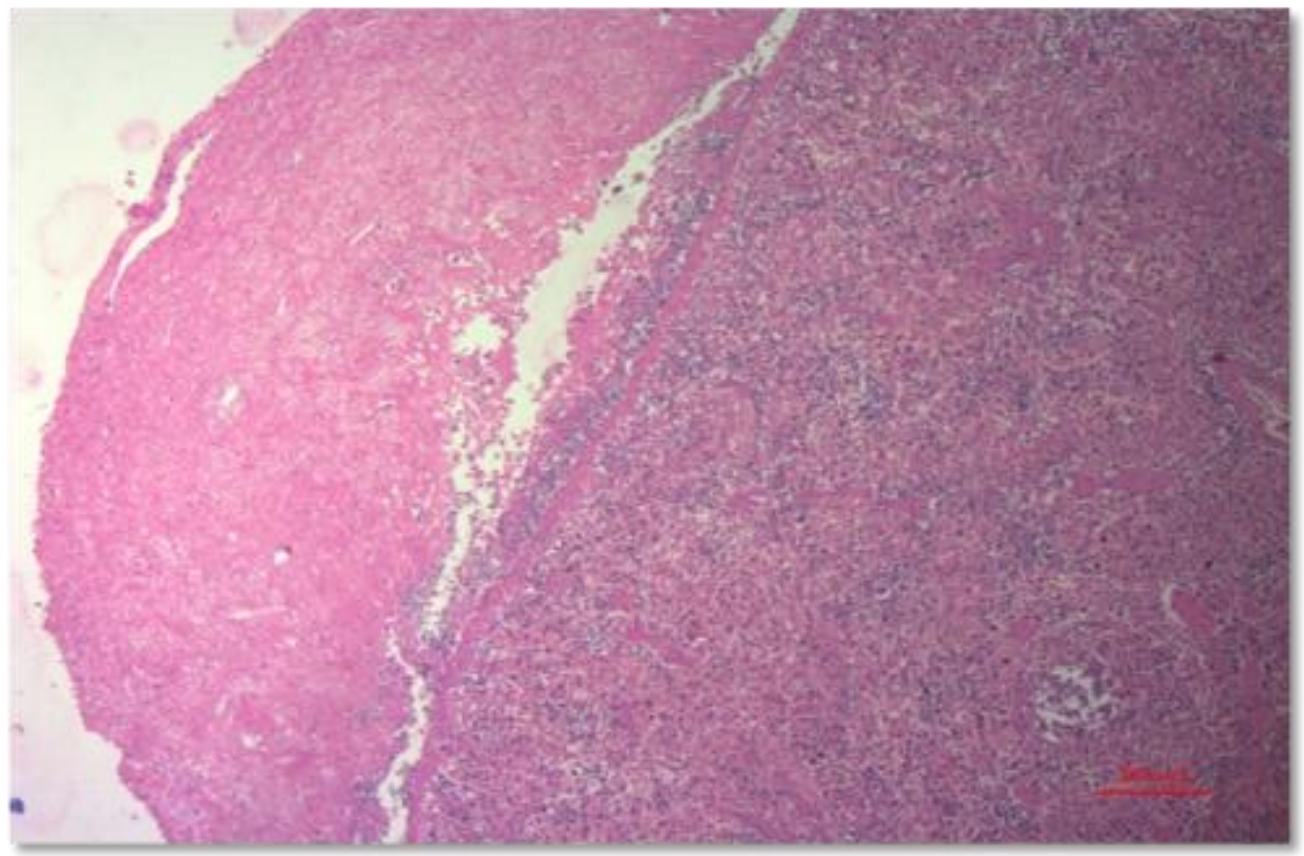

Fig.7 Multinucleated giant cell in nodule of spleen. H\&E

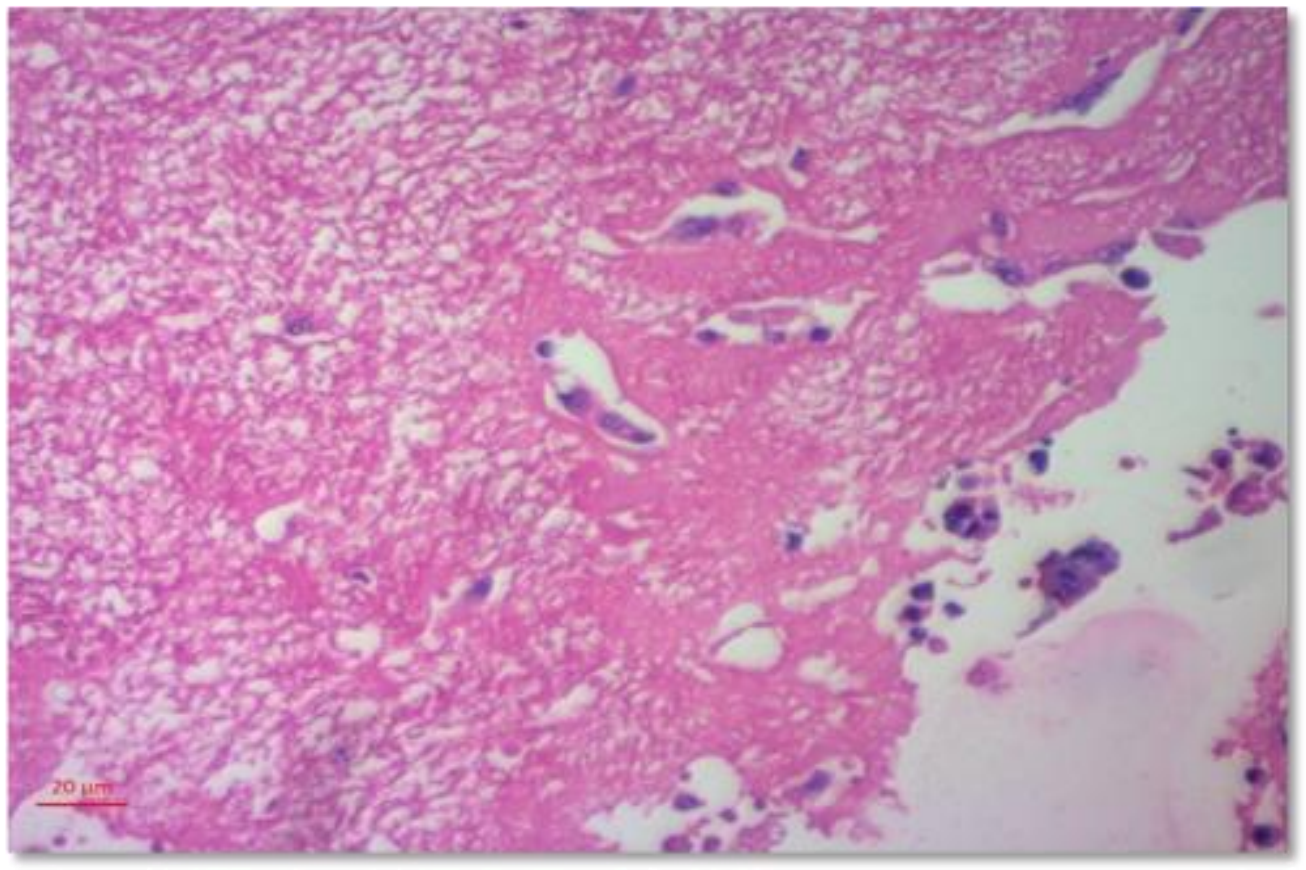


Fig.8 Depletion of lymphocytes from germinal centre in spleen. H\&E

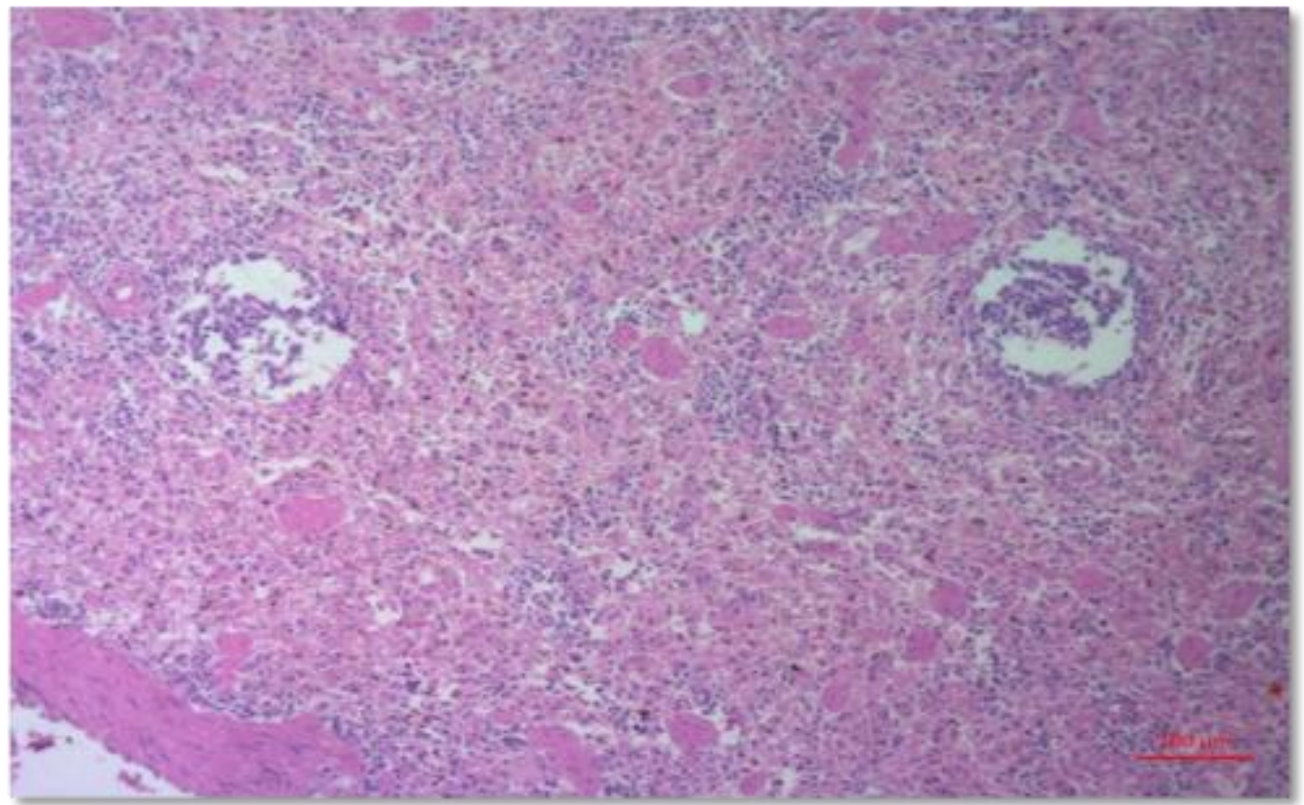

Fig.9 Fibrinous perihepatitis

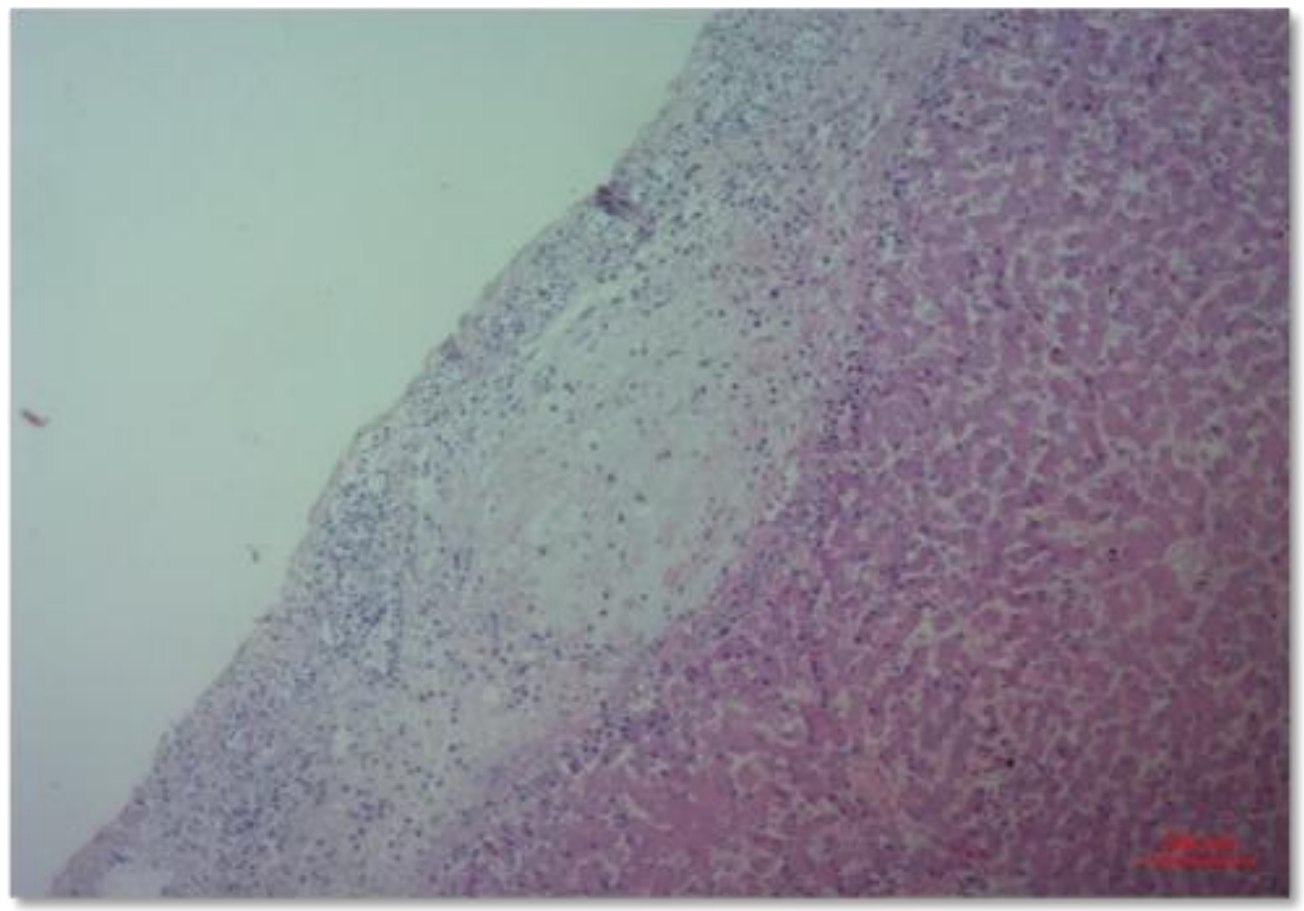


Fig.10 Focal necrosis in liver parenchyma. H\&E

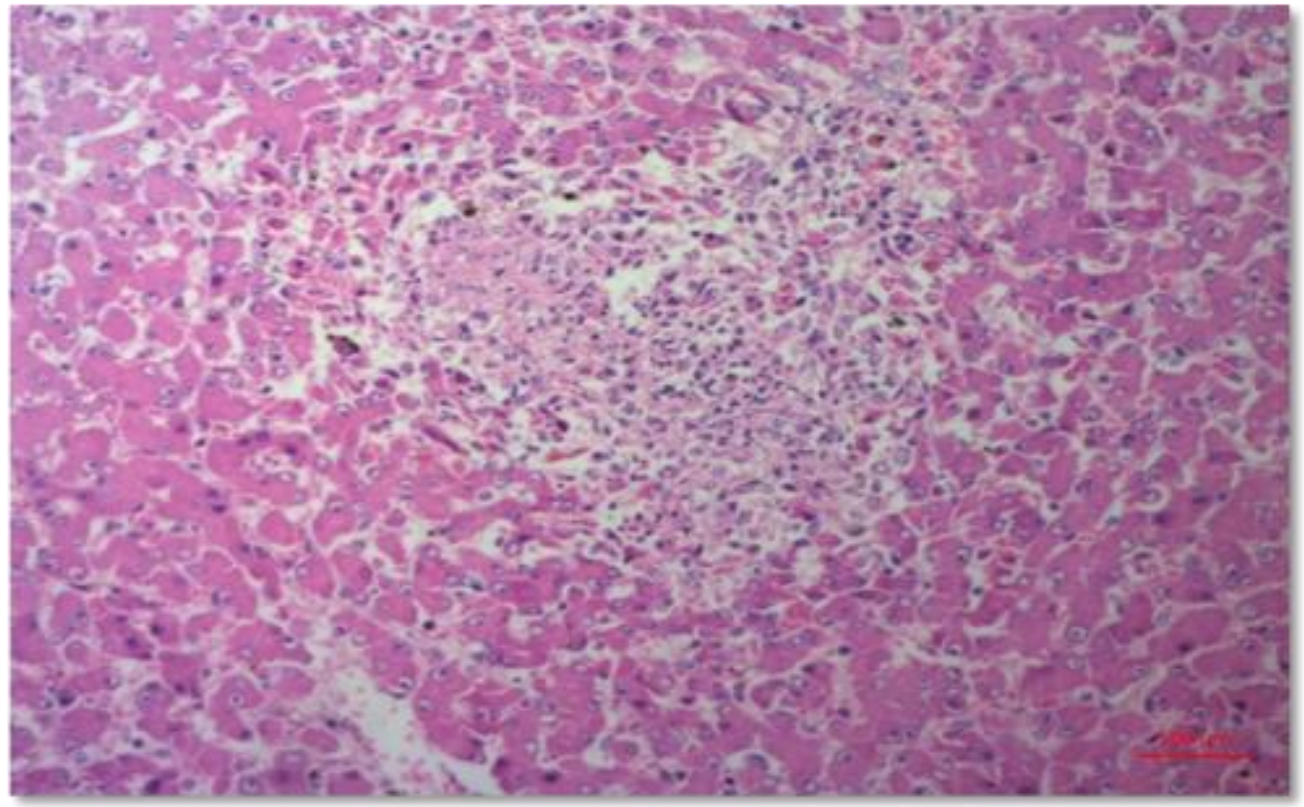

Fig.11 Vasculitis in Liver. H\&E

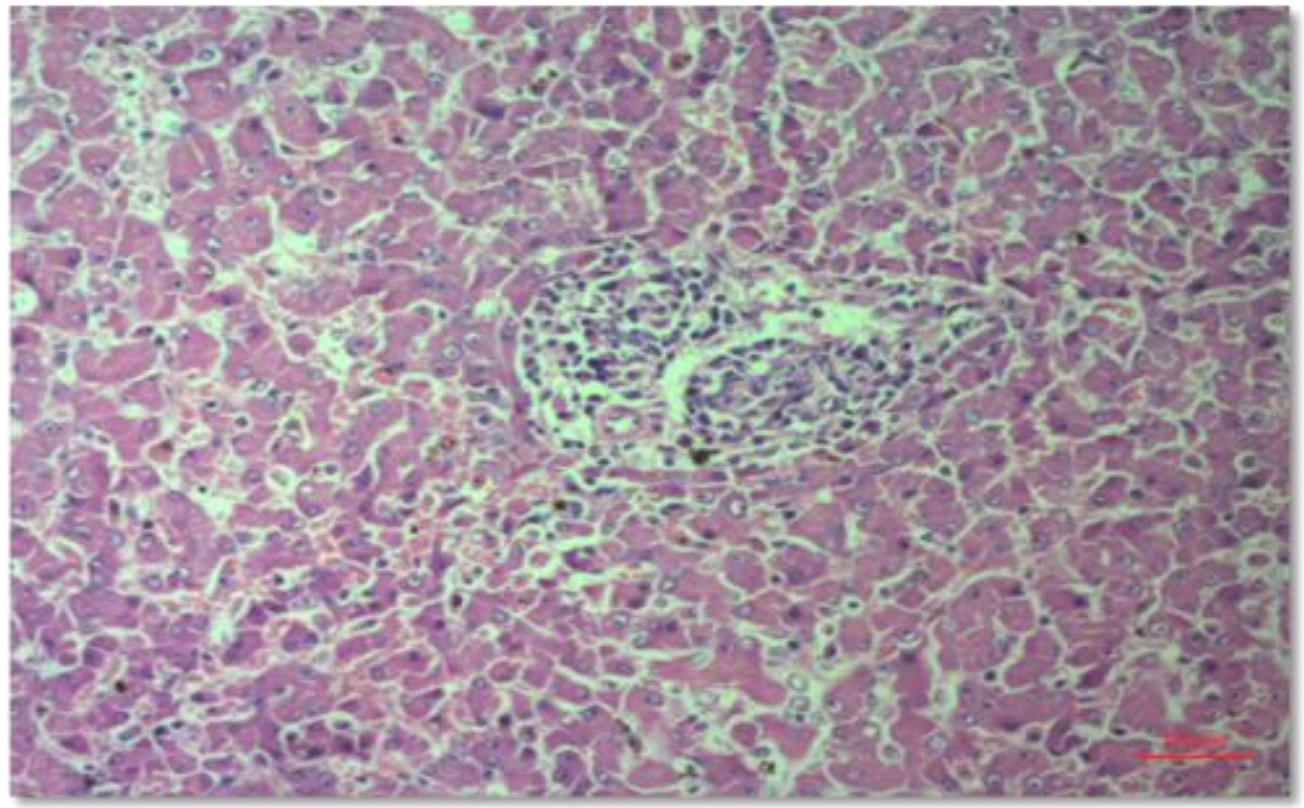

Liver contained multiple distinct foci of coagulative necrosis along with infiltration of leukocyte (Fig. 10). Which often results into hyperbilirubinaemia and icteric condition (Hartmann, 2003). Portal vein in liver showed necrosis and is occluded by leukocytes. Haemorrhages in its surrounding are evident
(Fig. 11). Histopathological findings observed in present study were similar earlier observations made by Montali and stramdberg, (1972). Histopathological findings are vital diagnostic tool for FIP, mostly presented with fibrinous, granulomatous and Vasculitis (Norris, 2007). 
In conclusion, the anamnesis, gross findings and histopathological findings were most indicative of FIP. Histopathological lesions and extent of damage caused to visceral organs made the young male cat to succumb. FIP is rare and consequences are fatal as there is no effective treatment available. Further research is required to overcome the challenges posed by FIP.

\section{References}

Addie, D., Belák, S., Boucraut-Baralon, C., Egberink, H., Frymus, T., GruffyddJones, T. and Marsilio, F. (2009). Feline infectious peritonitis. ABCD guidelines on prevention and management. Journal of Feline Medicine \& Surgery, 11(7), 594-604.

Benetka, V., Kübber-Heiss, A., Kolodziejek, J., Nowotny, N., Hofmann-Parisot, M. and Möstl, K. (2004). Prevalence of feline coronavirus types I and II in cats with histopathologically verified feline infectious peritonitis. Veterinary microbiology, 99(1), 31-42.

Haagmans, B. L., Egberink, H. F. and Horzinek, M. C. (1996). Apoptosis and T-cell depletion during feline infectious peritonitis. Journal of virology, 70(12), 8977-8983.

Hartmann K, Binder C, Hirschberger J, et al. Comparison of different tests to diagnose feline infectious peritonitis. $\mathbf{J}$ Vet Intern Med 2003; 17: 781-90.
Hartmann, K. (2005). Feline infectious peritonitis. Veterinary Clinics: Small Animal Practice, 35(1), 39-79.

Kipar, A., and Meli, M. L. (2014). Feline infectious peritonitis: still an enigma?. Veterinary pathology, 51(2), 505-526.

Luna, L. G. (1968), Manual of Histologic Staining Methods of the Armed Forces Institute of Pathology, 3rd Edition, pp. 71-98, McGraw Hill Book Co., New York

Montali, R. J., and Strandberg, J. D. (1972). Extraperitoneal lesions in feline infectious peritonitis. Veterinary pathology, 9(2), 109-121.

Norris, J. (2007). Updates in FIP: Pathogenesis, diagnosis and treatment. In Proceedings of the WSAVA Congress, Sydney, Australia.

Pedersen, N. C. (2009). A review of feline infectious peritonitis virus infection: 1963-2008. Journal of feline medicine and surgery, 11(4), 225-258.

Rohrbach, B. W., Legendre, A. M., Baldwin, C. A., Lein, D. H., Reed, W. M., and Wilson, R. B. (2001). Epidemiology of feline infectious peritonitis among cats examined at veterinary medical teaching hospitals. Journal of the American Veterinary Medical Association, 218(7), 1111-1115.

Wolfe LG, Griesemer RA. (1966): Feline infectious peritonitis. Veterinary Pathology., 3:255-270

\section{How to cite this article:}

Pankaj Gaonkar, Noopur Halmare, Siddhart Jamdade, Prashant Sonkusale and Nitin Kurkure. 2019. Feline Infectious Peritonitis in a Male Persian Cat. Int.J.Curr.Microbiol.App.Sci. 8(01): 1446-1453. doi: https://doi.org/10.20546/ijcmas.2019.801.154 